\title{
Germination and Early Seedling Growth of Rare Zamia spp. in Organic and Inorganic Substrates: Advancing Ex Situ Conservation Horticulture
}

\author{
Claudia Calonje ${ }^{1}$, Chad Husby ${ }^{2,4}$, and Michael Calonje ${ }^{3}$ \\ Montgomery Botanical Center, 11901 Old Cutler Road, Miami, FL 33156
}

Additional index words. container cultivation, sand, arcillite, calcined clay, Turface ${ }^{\circledR}$ MVP ${ }^{\circledR}$, aeration, cycads, inert substrates

\begin{abstract}
Improved propagation methods greatly benefit conservation of rare cycads. Appropriate substrate conditions, especially excellent root aeration, are crucial to successful cultivation of most cycads. Typical cycad substrates include substantial portions of organic materials that will decompose over time, reducing drainage and increasing water retention. In this study, two inorganic substrates, arcillite (Turface $\AA$ MVP ${ }^{\circledR}$ ) and coarse silica sand, and one mixed cycad substrate (with organic and inorganic components) were evaluated for germination and growth of three rare Zamia species: Z. fairchildiana L.D. Gómez, $Z$. cunaria Dressler \& D.W. Stev., and $Z$. aff. portoricensis Urb. over a period of 14 months from seed sowing. Substrate type affected leaves per seedling and leaf length. These factors also varied by species as did taproot length and germination rate. There were also significant interactions between substrate and species for caudex diameter and leaf variables, likely reflecting ecological differences among the species, two of which are from rainforest habitats and one from dry forest. All three substrates performed adequately for germination, survival, and growth of Zamia. Turface ${ }^{\circledR}$ and possibly the silica sand likely require additional watering to improve their performance as cycad substrates.
\end{abstract}

As a result of the vulnerability of wild cycad populations to human impacts, including collection for commercial horticulture, the Cycad Specialist Group of the International Union for Conservation of Nature (IUCN) recommends concerted efforts to improve propagation and cultivation of cycads (Donaldson et al., 2003). With this conservation concern in mind, important progress has been made in cycad horticulture (Chavez and Litz, 2007; Dehgan, 1983, 1999; Dehgan and Johnson, 1983; Witte, 1977), but to date, no studies appear to have been published investigating the effects of different substrates on cycad growth and development. The objective of this study was to determine whether use of

Received for publication 1 Sept. 2009. Accepted for publication $2 \mathrm{Feb} .2010$.

Financial and logistical support for this project was provided by the Montgomery Botanical Center. Mention of a trademark, proprietary product, or vendor does not constitute a guarantee or warranty of the product by the Montgomery Botanical Center and does not imply its approval to the exclusion of other products or vendors that also may be suitable.

We thank Vickie Murphy for taking care of the plants during the experiment. We also thank Sara Edelman and Arantza Strader for assistance with substrate physical properties measurements.

${ }^{1}$ Collections Specialist.

${ }^{2}$ Collections Manager and Botanist.

${ }^{3}$ Cycad Biologist.

${ }^{4}$ To whom reprint requests should be addressed; e-mailchad@montgomerybotanical.org.
$100 \%$ inorganic substrates will lead to an improvement in germination or growth of rare Zamia spp. in containers.

Providing the proper balance of aeration, water retention, nutrient-holding capacity, and decomposition rate are among the key factors that must be considered in evaluating a cycad container substrate. Excellent drainage is especially crucial, because cycads often do best in "sandy gravelly" soils (Whitelock, 2002). As a result of the slow growth of cycads, the ability of a substrate to retain its physical properties over time is crucial, especially in a hot, humid environment such as south Florida that accelerates decomposition of organic materials. Drainage of organic container substrates can decline considerably over time as the substrate decomposes (Bilderback et al., 2005). Thus, it seems likely that an ideal long-term cycad substrate would be inorganic and resistant to decay or at least contain a sufficiently high proportion of inorganic materials to retain drainage even after the organic components have begun significant decomposition.

The Montgomery Botanical Center (MBC) is a 120 -acre botanical garden in Miami, FL, that specializes in conservation horticulture of cycads and palms. Montgomery currently cultivates two-thirds of extant cycad species and expends considerable effort propagating and growing cycads in containers as well as in the ground. Historically, MBC has used a horticultural mix comprised of equal parts organic soil conditioner (Fafard Organic Soil Conditioner; Conrad Fafard, Inc., Agawam, MA), silica-based coarse building sand (6/20 grade; Florida Silica and Sand Company, Ft. Lauderdale, FL), and expanded clay pellets (Hydroton ${ }^{\circledR}$ 8/16 mm grade; Ökotau Easy Green $\mathrm{GmbH}$, Eschborn, Germany) as a substrate for both seed germination and nursery container culture of cycads.

In the current study, two other substrates, Turface $\AA$, a calcined montomorillinite clay (Turface ${ }^{\circledR}$ MVP $\AA$; Profile Products LLC, Buffalo Grove, IL), also known as arcillite, and coarse silica sand (6/20 grade; Florida Silica and Sand Company), were selected for comparison with MBC's horticultural mix (referred to as "cycad mix") to evaluate the effects of inorganic substrates versus a typical mixed organic-inorganic substrate on germination and early seedling growth. Sand and Turface ${ }^{\circledR}$ have both shown considerable promise in hydroponic applications, and some horticulturists have used them successfully for growing cycads and succulents. As a result of their physical and chemical stability, these products are of interest to evaluate for their potential as long-term substrates for cycad culture.

Turface ${ }^{\circledR}$ is a calcined montmorillinite clay soil conditioner designed for use as an amendment or top-dressing for turf in sports fields. It is meant to hold moisture and nutrients, increase drainage, and reduce compaction. Calcined clay has long been known to be an excellent substrate for growth of experimental plants in hydroponics (Jaeger, 1981), partly because it allows easy separation of the substrate from the root system (Hiller and Koller, 1979) while also supporting good growth. Warren and Bilderback (1992) and Owen et al. (2008) found that calcined clay reduces water use and increases fertilizer efficacy in container production when used as a substrate amendment. Turface ${ }^{\circledR}$ has excellent drainage, porosity, and water-holding capacity (Table 1), is mechanically stable, and has high cation exchange capacity as a result of its montmorillinite clay makeup (Warren and Bilderback, 1992).

Coarse silica building sand is often used as a germination substrate. One grower reported exceptional growth of cycads in $100 \%$ sand (T. Broome, personal communication), including difficult Macrozamia species that are especially sensitive to lack of drainage (Broome, 2006). The excellent drainage and inertness of sand render it promising for cycad culture. Sand has long been used as a standalone substrate in a very broad range of hydroponic research (Hewitt, 1966).

\section{Materials and Methods}

The experiment took place in a shadehouse at MBC. Seeds from three different taxa of Zamia, collected in situ for cultivation in MBC's ex situ conservation collection, were used in the experiment: Zamia fairchildiana seeds from Panama near the Costa Rican border, Zamia cunaria from two populations in Panama (Wargandí and Kuna Yala provinces), and Zamia aff. portoricensis from northwestern Jamaica. The later taxon is known in the horticultural trade as 'Jamaican Giant'. 
Seeds from individual mother plants were collected separately, received a unique accession number based on the mother plant, and were sown separately for the experiment. Seeds from each accession were separated into three treatment groups (MBC cycad mix, $100 \%$ sand, and $100 \%$ Turface ${ }^{\circledR}$ MVP $\left.{ }^{\circledR}\right)$ and planted in $2.6-\mathrm{L}$ pots in a shadehouse $(50 \%$ shade) under identical environmental conditions. The MBC cycad mix consisted of 1 coarse pine bark: 1 silica sand (6/20):1 organic soil conditioner (made from pine bark):1 Hydroton ${ }^{\circledR}$ clay pellets $(8 / 16 \mathrm{~mm})$ (by volume). Each substrate had different physical properties (Table 1) and particle size distribution (Table 2). Containers were fertilized once for the duration of the experiment after natural seed abscission with $14.8 \mathrm{~cm}^{3}$ Nutricote ${ }^{\circledR}$ 18N-2.6P-6.6K (Chisso-Asahi Fertilizer Co., Ltd., Tokyo, Japan) controlledrelease fertilizer with micronutrients. Pots were watered thoroughly beyond container capacity (until water drained freely from the container) three times per week (Monday, Wednesday, Friday) with automatic overhead irrigation. All containers received the same irrigation treatment.

Physical properties of the container substrates were measured after the completion of the experiment on fresh cycad mix like that used in the experiment and on the same sand and Turface ${ }^{\circledR}$ product grades as used in the experiment. Three replicates of 500-mL samples for each substrate were used for physical

Table 1. Physical properties of substrates used for growing Zamia spp.: Montgomery Botanical Center cycad mix, sand, and Turface ${ }^{\circledR}$ MVP ${ }^{\circledR}{ }^{z}$

\begin{tabular}{lccc}
\hline & Cycad mix & Sand & Turface® MVP® \\
\hline Air space & $28.7 \% \mathrm{a}$ & $8.7 \% \mathrm{~b}$ & $16.3 \% \mathrm{c}$ \\
Water-holding capacity & $14.5 \% \mathrm{a}$ & $29.9 \% \mathrm{~b}$ & $40.3 \% \mathrm{c}$ \\
Total porosity & $43.1 \% \mathrm{a}$ & $38.5 \% \mathrm{a}$ & $56.7 \% \mathrm{~b}$ \\
Bulk density $\left(\mathrm{g} \cdot \mathrm{mL}^{-1}\right)$ & $0.56 \mathrm{a}$ & $1.75 \mathrm{~b}$ & $0.71 \mathrm{c}$ \\
\hline
\end{tabular}

${ }^{\mathrm{Z}}$ Different letters indicate significant pairwise differences between substrate means (Tukey's honestly significant difference, $\alpha=0.05$ ).

Table 2. Particle size distribution of cycad mix, coarse sand (Florida Silica \& Sand Company, 6/20), and Turface ${ }^{\circledR}$ MVP ${ }^{\circledR}$ used in the Zamia substrate experiment. ${ }^{\mathrm{z}}$

\begin{tabular}{rcccc}
\hline Sieve no. & $\begin{array}{c}\text { Hole } \\
\text { diam }(\mathrm{mm})\end{array}$ & $\begin{array}{c}\text { Percent } \\
\text { retained } \\
\text { (cycad mix) }\end{array}$ & $\begin{array}{c}\text { Percent } \\
\text { retained } \\
\text { (sand) }\end{array}$ & $\begin{array}{c}\text { Percent retained } \\
\left.\text { (Turface }{ }^{\circledR} \text { MVP } \AA\right)\end{array}$ \\
\hline $5(P<0.0001)$ & 4 & $35.0 \mathrm{a}$ & $0 \mathrm{~b}$ & $0 \mathrm{~b}$ \\
$10(P<0.0001)$ & 2 & $8.35 \mathrm{a}$ & $2.54 \mathrm{~b}$ & $67.2 \mathrm{c}$ \\
$35(P<0.0001)$ & 0.5 & $52.9 \mathrm{a}$ & $97.3 \mathrm{~b}$ & $32.8 \mathrm{c}$ \\
$60(P<0.0001)$ & 0.25 & $2.28 \mathrm{a}$ & $0.10 \mathrm{~b}$ & $0 \mathrm{c}$ \\
$120(P<0.0001)$ & 0.125 & $0.78 \mathrm{a}$ & $0.04 \mathrm{~b}$ & $0 \mathrm{~b}$ \\
$>120(P<0.0001)$ & 0.63 & $0.68 \mathrm{a}$ & $0 \mathrm{~b}$ & $0 \mathrm{~b}$ \\
\hline
\end{tabular}

${ }^{\mathrm{z}} P$ values in parentheses are for analyses of variance at each sieve size. Different letters indicate significant pairwise differences between substrates (Tukey's honestly significant difference, $\alpha=0.05$ ).

Table 3. a) Sowing rates and number of experimental pots for each Zamia species: (number of pots) $\times$ (number of seeds per pot) for each species/substrate combination; and $b$ ) total seedlings and number of experimental pots for each Zamia species for each species/substrate combination.

\begin{tabular}{|c|c|c|c|c|}
\hline & & $\begin{array}{c}\text { Zamia } \\
\text { fairchildiana }\end{array}$ & $\begin{array}{c}\text { Zamia } \text { aff. } \\
\text { portoricensis }\end{array}$ & $\begin{array}{c}\text { Zamia } \\
\text { cunaria }\end{array}$ \\
\hline \multirow[t]{3}{*}{ a) Sowing rates } & Cycad mix & $1 \times 5,1 \times 6$ & $6 \times 10$ & $4 \times 10,1 \times 5$ \\
\hline & Sand & $3 \times 5$ & $6 \times 10$ & $2 \times 10,1 \times 11,1 \times 15$ \\
\hline & Turface $®$ & $2 \times 5$ & $6 \times 10$ & $3 \times 10,2 \times 11,1 \times 5$ \\
\hline \multirow{3}{*}{$\begin{array}{l}\text { b) Total seedlings } \\
\text { and number of pots }\end{array}$} & Cycad mix & 10 (2 pots) & 55 (6 pots) & 32 (5 pots) \\
\hline & Sand & 21 (4 pots) & 57 (6 pots) & 39 (4 pots) \\
\hline & Turface $\AA$ & 10 (2 pots) & 58 (6 pots) & 42 (6 pots) \\
\hline
\end{tabular}

of $Z$. cunaria) and five to six per pot for $Z$. fairchildiana (Table 3). Differences in sowing rates reflected differences in seed size and different amounts of available seeds from field collection. A separate experiment (data not shown) indicated that sowing rates of five to 11 seeds/pot did not significantly affect germination, establishment, or early growth for the three species studied. The numbers of seedlings and pots per treatment are given in Table 3. Community pots were evaluated for seed germination, and seedlings were evaluated by measuring caudex diameter, taproot length, leaf number, leaf length, and number of leaflet pairs on the largest leaf (see Fig. 1 for typical cycad seedling morphology).

Statistical analyses were carried out using JMP ${ }^{\circledR}$ 8.0.1 (SAS Institute, Inc., Cary, NC). For substrate physical properties, percentages were transformed using the standard arcsine transformation for proportions before analysis (Quinn and Keough, 2002). For each property, an analysis of variance (ANOVA) followed by a multiple comparisons test [Tukey's honestly significant difference (HSD)] was performed to distinguish among the substrates. The experiment was factorial in a completely randomized design with substrate, number of seeds sown per pot, and species being the factors. Individual seedlings, rather than pots, were treated as replicates. This was done because during the first year of growth, root development remains sparse in Zamia, minimizing interactions among seedlings in a given pot. Also, because the substrates were uniformly prepared, variation from pot to pot within each substrate treatment was considered negligible. Assumptions akin to this are also made implicitly when analyzing experiments when each seedling has its own pot, because there are always factors beyond the treatments that can plausibly "carry over" from one

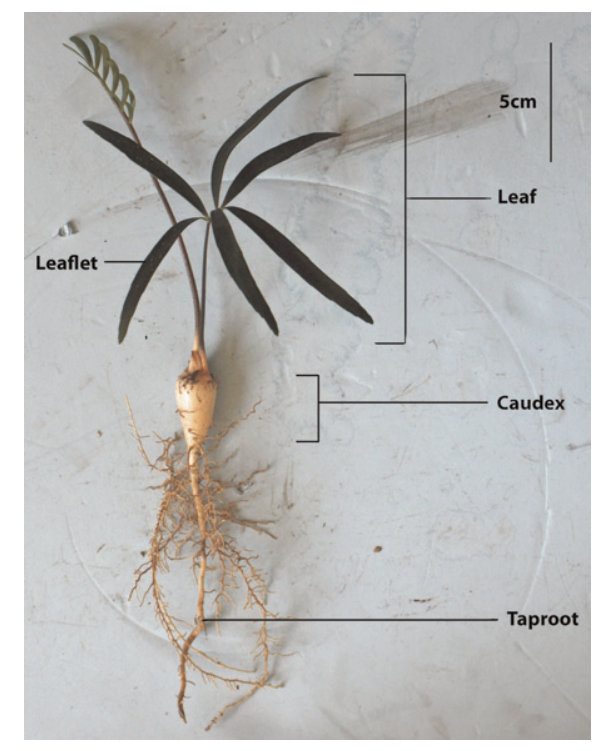

Fig. 1. Zamia aff. portoricensis seedling grown in Turface $\AA$. This individual exhibits typical seedling morphology with one mature and one developing leaf. 
apparent replicate to the next (Oksanen, 2004). Also, cycad seeds are normally sown in community pots at $\mathrm{MBC}$ and elsewhere so it was considered more desirable to accurately recreate normal nursery practices rather than to sow each seed in an individual pot. This is a natural tradeoff between classic replication (one seed or seedling per pot) and applicability of the experiment to actual growing conditions (Oksanen, 2001).

We performed separate ANOVAs on each continuous response variable using the full factorial model (except for germination rate, in which a model without interactions was used, because the interaction model was not significant) using Type III sums of squares (partial sums of squares) to test hypotheses. For the count response data (number of leaves and leaflet pairs), an ordinal logistic model was used because of the large number of repeated values that render the ANOVA assumptions invalid. The ordinal logistic model is conservative in the case of count data (Sturman, 1999). For continuous variables, pairwise means comparisons were performed using Tukey's HSD. In addition, for the initial experiment, a separate ANOVA was performed to test for differences in germination rates and sowing rates among substrates after using the standard arcsine transformation for proportions. Where feasible, model assumptions were checked through residual plots.

\section{Results}

Air space $(P<0.0001)$, water-holding capacity $(P<0.0001)$, total porosity $(P=$ $0.001)$, and bulk density $(P<0.0001)$ differed significantly among substrates. Tukey's HSD $(\alpha=0.05)$ detected significant pairwise differences among all substrate pairs except for total porosity, which was not detectably different between cycad mix and sand (Table 1). Particle size distribution also varied significantly among substrates at each mesh size (Table 2).

Germination rates did not vary significantly among substrates $(P=0.163)$ but did vary significantly among species $(P=$ $0.0056)$ with the lowest germination rate for Zamia cunaria $(80.4 \%, \mathrm{n}=180)$ in contrast to $Z$. aff. portoricensis $(94.4 \%, \mathrm{n}=163)$ and Z. fairchildiana $(94.7 \%, \mathrm{n}=36)$. Pairwise means comparisons are given in Table 4.

Caudex diameter differed significantly among species $(P<0.001$; Fig. 2$)$. Tukey's HSD determined that all pairwise species means were significantly different at the $\alpha=0.05$ level (Table 4). However, there were no significant differences among substrates across species $(P=0.10)$. There was a significant species $\times$ substrate interaction $(P=$ 0.005; Fig. 2).

Substrate type affected number of leaves per seedling $(P<0.0001)$ as did species $(P<$ $0.0001)$. Furthermore, there was a significant interaction between species and substrate ( $P<0.0001$; Fig. 3).

Substrate type also affected length of longest seedling leaf $(P=0.0093)$ as did
Table 4. Significant pairwise least squares means comparisons between species using Tukey’s honestly significant difference. ${ }^{z}$

\begin{tabular}{lcccc}
\hline & Caudex & Leaf & Taproot \\
& Germination $(\%)$ & diam $(\mathrm{mm})$ & $\begin{array}{c}\text { length }(\mathrm{cm}) \\
\text { length }(\mathrm{cm})\end{array}$ \\
\hline Zamia fairchildiana & $95 \% \mathrm{a}$ & $23.7 \mathrm{a}$ & $27.1 \mathrm{a}$ & $20.4 \mathrm{a}$ \\
Zamia aff. portoricensis & $94 \% \mathrm{a}$ & $17.5 \mathrm{~b}$ & $14.6 \mathrm{~b}$ & $11.4 \mathrm{~b}$ \\
Zamia cunaria & $80 \% \mathrm{~b}$ & $11.8 \mathrm{c}$ & $8.8 \mathrm{c}$ & $9.6 \mathrm{c}$ \\
\hline
\end{tabular}

${ }^{2}$ Different letters represent significant differences at the $\alpha=0.05$ level.

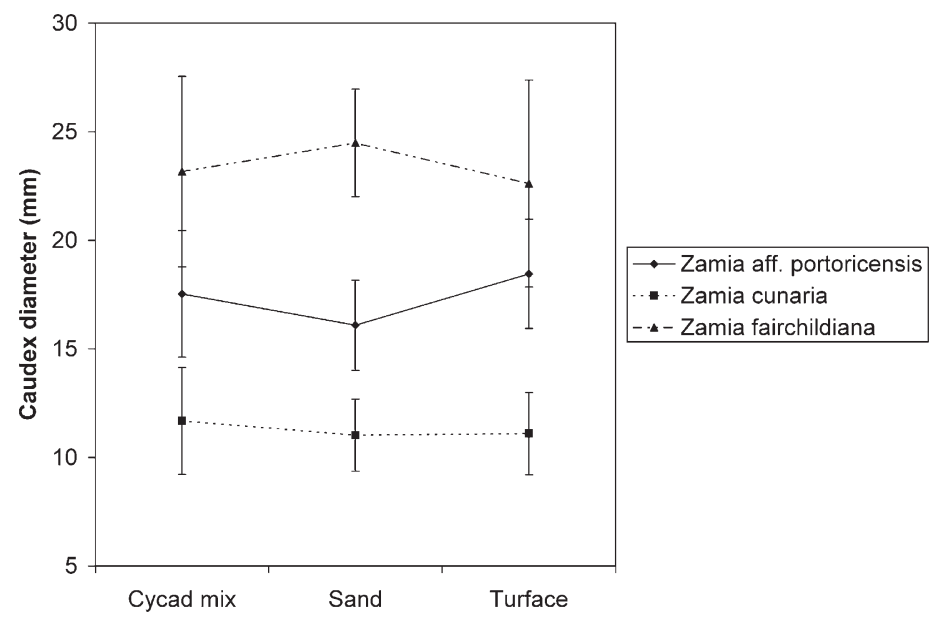

Fig. 2. Means and SDs for Zamia seedling caudex diameter for plants grown in three different substrates.

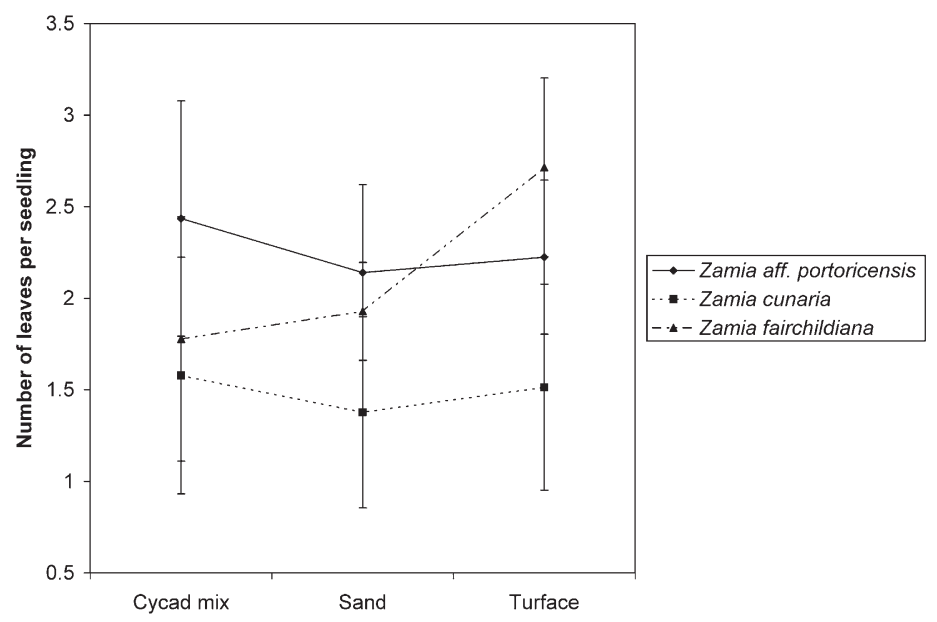

Fig. 3. Means and sDs for number of leaves per Zamia seedling for plants grown in three different substrates.

species $(P<0.0001)$. These factors also interacted to affect leaf length $(P<0.001$; Fig. 4). All pairwise species comparisons were significant for species (Table 4). However, for substrate, the only significant pairwise difference was between cycad mix (mean leaf length $=17.9 \mathrm{~cm}$ ) and Turface $\AA$ (mean leaf length $=15.6 \mathrm{~cm}$ ).

Number of leaflet pairs on the longest seedling leaf was affected by species $(P<$ $0.0001)$ but not by substrate $(P=0.152)$. There was also a significant substrate $\times$ species interaction $(P=0.0031$; Fig. 5$)$.

Taproot length varied significantly by species $(P<0.001$; Fig. 6$)$ but not by substrate. All pairwise means comparisons were significant at the $\alpha=0.05$ level (Table 4 ).

\section{Discussion}

The substrates used in this study contrasted strongly in their properties. The MBC cycad mix contains organic matter and retains moisture well between waterings, although the actual water-holding capacity is less than the other substrates (Table 1). Turface $\AA$, in contrast, dries quickly between waterings when used alone despite its relatively high water-holding capacity (Table 1) in contrast to its behavior as an amendment in organic mixes found by Owen et al. (2008) and Bilderback et al. (2005). This is likely the result of the highly porous structure of Turface ${ }^{\circledR}$ and its high proportion of coarse particles (Table 2) when used alone. This 


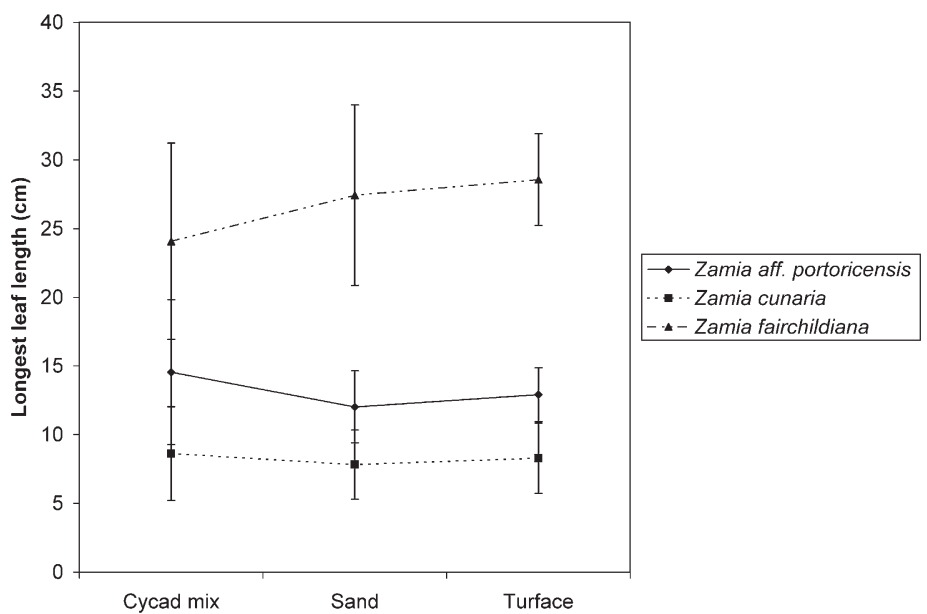

Fig. 4. Means and SDs for length of longest Zamia seedling leaf for plants grown in three different substrates.

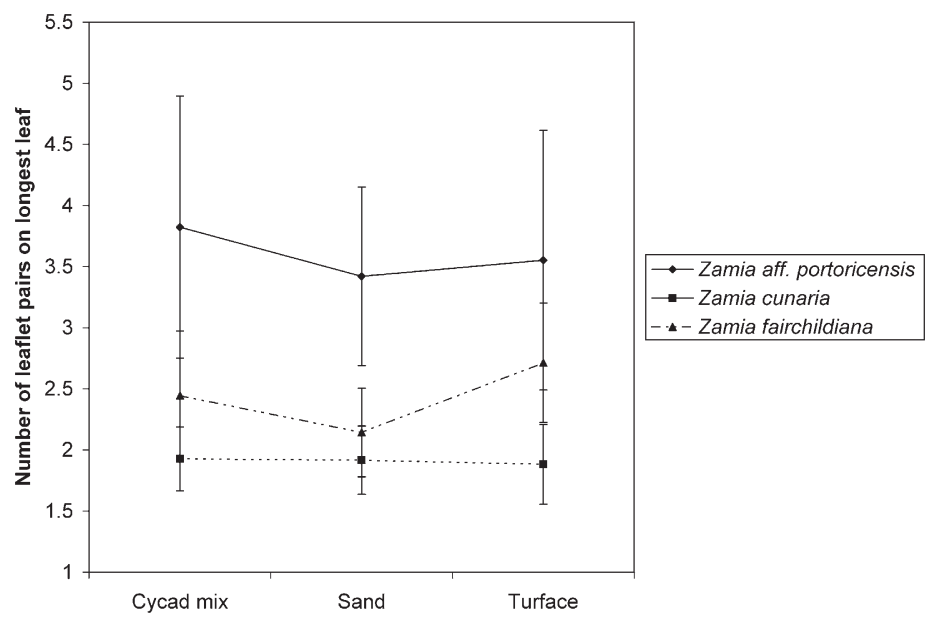

Fig. 5. Means and sDs for number of leaflet pairs of longest Zamia seedling leaf for plants grown in three different substrates.

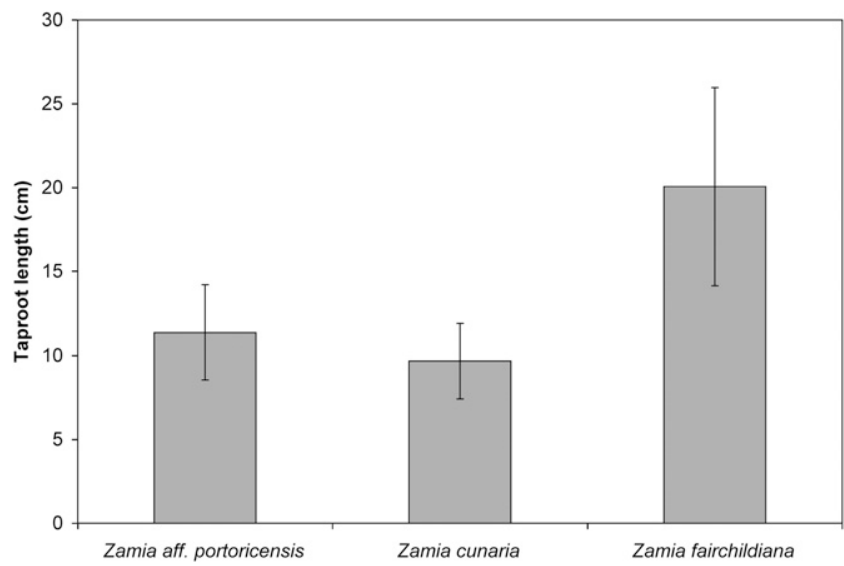

Fig. 6. Means and sDs for Zamia seedling taproot lengths averaged across substrates.

creates a high surface area for evaporation, leading to increased air circulation in the substrate and more rapid drying. Turface ${ }^{\circledR}$ itself is free of organic matter.

Coarse silica sand retains more moisture between waterings than does Turface $\AA$, likely as a result of its lower porosity (Table
1) related to its higher proportion of finer particles (Table 2), but dries more quickly than MBC cycad mix despite the higher porosity of the cycad mix (Table 1). However, all substrates were watered according to a schedule designed for MBC cycad mix (three waterings per week, every other day except during weekends). This may partly account for why the average number of leaves (Fig. 5) per seedling was higher for MBC cycad mix (2.59) than for sand (1.86) or Turface ${ }^{\circledR}$ (2.02). Similar patterns appeared for leaf length $(17.37 \mathrm{~cm}$ cycad mix, 12.96 $\mathrm{cm}$ sand, and $12.85 \mathrm{~cm}$ Turface $\left.{ }^{\circledR}\right)$ and number of leaflet pairs on the largest leaf (3.65 cycad mix, 2.84 sand, and 2.92 Turface $\left.{ }^{\circledR}\right)$. The high proportion of coarse material in cycad mix (Table 2), which helped create a high amount of air space (Table 1), combined with long water retention was clearly beneficial for the Zamia species tested. A substrate that has a high proportion of coarse material but is largely inorganic so that it does not break down over the long production cycles of Zamia, would be ideal. However, adjustment should be made to the watering regime to ensure that it does not dry out too quickly as was the case for Turface ${ }^{\circledR}$ in this experiment.

The leaves of Zamia fairchildiana seedlings in Turface ${ }^{\circledR}$ were twisted down and the petioles bent. This was possibly the result of the more rapid drying of the Turface ${ }^{\circledR}$ than the sand or cycad mix, causing intermittent water stress. The tendency of Turface ${ }^{\circledR}$ to dry quickly when used as the sole substrate component was observed in a prior experiment with bromeliad cultivation (Sard, 1989). However, the number of leaves, length of the longest leaf, and number of leaflet pairs of $Z$. fairchildiana were greater in Turface ${ }^{\circledR}$ than in the other substrates (Fig. 3), suggesting that intermittent drought stress may stimulate increased leaf production and elongation without much affecting caudex diameter (Fig. 2). This response is surprising because the typical response of droughttolerant trees to water stress is to allocate more resources to below-ground biomass and less to leaves (Markesteijn and Poorter, 2009). The same is the case for droughttolerant grasses (Kalapos et al., 1996). Because $Z$. fairchildiana is considered to be a relatively fast-growing rainforest species (Whitelock, 2002), likely with high water requirements, its reaction to the sometimes droughty Turface ${ }^{\circledR}$ substrate seems to have been more marked than the other species. This is the case despite its markedly longer taproot (Fig. 6), that might have been expected to compensate for the droughty conditions by accessing moisture available deeper in the substrate. Overall, the unusual reaction of $Z$. fairchildiana to Turface ${ }^{\circledR}$ seems to have been counterproductive and may have contributed to its pronounced leaf curling. Increased irrigation would be especially crucial for this species when grown in Turface ${ }^{\circledR}$.

For most growth variables, the three species included in this study reacted differently to the different substrates. Zamia aff. portoricensis had larger diameter caudices in Turface $\AA$ than in the other substrates, whereas the other two species did not (Fig. 2). This may be related to differences in rainfall in their respective habitats with $Z$. cunaria and $Z$. fairchildiana coming from rainforest areas 
(Whitelock, 2002) and Z. aff. portoricensis from a tropical dry forest habitat (M. Calonje, personal observations, 2008). Because Turface ${ }^{\circledR}$ was the most drought-prone substrate used in the study, $Z$. aff. portoricensis was likely the best adapted to it. The leaf variables bore this out because $Z$. aff. portoricensis had slightly fewer and smaller leaves in Turface ${ }^{\circledR}$ and sand than in cycad mix (Figs. 3, 4, and 5). This shows its ability to plastically reduce its leaf area and increase its caudex size under drought conditions. Allocation of greater resources to underground storage tissue rather than leaf area is one of several important adaptations to drought because this reduces the overall surface area to volume ratio of the plant in addition to reducing exposure to desiccating air and hence reduces water loss (Mauseth, 2000). Such a response is characteristic of drought-tolerant trees and grasses (Kalapos et al., 1996; Markesteijn and Poorter, 2009).

In contrast with $Z$. fairchildiana and $Z$. aff. portoricensis, $Z$. cunaria showed little response to the three substrates (Figs. 2-5). Zamia cunaria normally bears only one to three leaves in the wild, whereas $Z$. fairchildiana bears many and $Z$. aff. portoricensis bears two to five per caudex (Whitelock, 2002). Thus, it is not surprising that $Z$. cunaria exhibits little plasticity in response to substrate because it bears only a few leaves even in a lush rainforest habitat, suggesting that its ability to opportunistically take advantage of different conditions is limited. Correspondingly, its ability to plastically reduce its resources in response to drier conditions also appears limited.

It is likely that a more frequent watering schedule or placing a reservoir of water under the inorganic substrates would have improved the growth of Zamia in these substrates, especially in Turface $\AA$. Turface $\AA$ can be used successfully to grow very droughtsensitive plants if a water reservoir is provided to prevent drying out (C. Husby, personal observations). Because the substrate is inorganic, anaerobic decomposition of the substrate under saturated conditions does not occur, making a reservoir feasible as in hydroponics. In addition, it is likely that relative behavior of plants growing in the three substrates will vary over time, because the organic components of the MBC cycad mix decompose over time (Bilderback et al.,
2005), whereas the properties of the other two substrates remain constant. This may have implications not only for substrate physical properties, but also for root-rotting fungal pathogens that require high levels of moisture in the substrate. Furthermore, as the seedlings increase in size and in the extent of their root systems, their tolerance of sometimes droughty conditions in Turface ${ }^{\circledR}$ will likely increase, perhaps ameliorating the negative response to Turface ${ }^{\circledR}$ seen in Zamia fairchildiana seedlings. Thus, investigation of the responses of larger cycads to the three substrates is an area for future research.

The availability of the substrate components used in this study is likely to be low or nonexistent in most areas where cycads are grown worldwide. However, other inorganic materials such as pumice, perlite, other crushed porous materials, or fired clays may be used as substitutes to create substrates with similarly excellent drainage qualities to the ones used in this study. Coarse sand is likely to be available in many localities. Because cycads often grow on limestone substrates, sand with limestone can also be used with good success for many species. Peat and bark substitutes made from local organic materials (including composts and coconut coir) can substitute for the organic materials used in this study.

Optimizing substrates for cycad propagation is a critical step in ex situ conservation efforts. Predictability of optimal substrate and watering regime relative to native habitat can help increase efficient use of limited resources for these horticulturally unique living fossils.

\section{Literature Cited}

Bilderback, T.E., S.L. Warren, J.S. Owen, Jr, and J.P. Albano. 2005. Healthy substrates need physicals too. HortTechnology 15:747-751.

Broome, T. 2006. Growth medium. In: Haynes, J. (ed.). Virtual cycad encyclopedia, Chapter 5: Horticulture. 31 Aug. 2009. <http://www. plantapalm.com/vce/horticulture/medium.htm>.

Chavez, V.M. and R.E. Litz. 2007. Recovery of difficult-to-regenerate species: The cycad example. Acta Hort. 738:51-61.

Dehgan, B. 1983. Propagation and growth of cycads: A conservation strategy. Proc. Fl. State Hort. Soc. 96:137-139.

Dehgan, B. 1999. Propagation and culture of cycads: A practical approach. Acta Hort. 486: 123-131.
Dehgan, B. and C.R. Johnson. 1983. Improved seed germination of Zamia floridana (sensu lato) with $\mathrm{H}_{2} \mathrm{SO}_{4}$ and $\mathrm{GA}_{3}$. Scientia Hort. 19:357361.

Donaldson, J.S., B. Dehgan, A.P. Vovides, and W. Tang. 2003. Cycads in trade and sustainable use of cycad populations, p. 39-47. In: Donaldson, J.S. (ed.). Cycads: Status survey and action plan. IUCN, Gland, Switzerland.

Hewitt, E.J. 1966. Sand and water culture methods used in the study of plant nutrition, Technical Communication No. 22. 2nd Ed. Commonwealth Bureau of Horticulture and Plantation Crops, East Malling, Maidstone, Kent, UK.

Hiller, L.K. and D.C. Koller. 1979. Potato growth responses in arcillite and sand. HortScience 14: 534-536.

Jaeger, C.H. 1981. An improved medium for nutriculture incorporating arcillite. HortScience 15:176-177.

Kalapos, T., R. van den Boogaard, and H. Lambers. 1996. Effect of soil drying on growth, biomass allocation and leaf gas exchange of two annual grass species. Plant Soil 185:137-149.

Markesteijn, L. and L. Poorter. 2009. Seedling root morphology and biomass allocation of 62 tropical tree species in relation to droughtand shade-tolerance. J. Ecol. 97:311-325.

Mauseth, J.D. 2000. Theoretical aspects of surfaceto-volume ratios and water-storage capacities of succulent shoots. Amer. J. Bot. 87:11071115.

Oksanen, L. 2001. Logic of experiments in ecology: Is pseudoreplication a pseudoissue? Oikos 94:27-38.

Oksanen, L. 2004. The devil lies in the details: A reply to Stuart Hurlbert. Oikos 104:598-605.

Owen, J.S., S.L. Warren, T.E. Bilderback, and J.P. Albano. 2008. Phosphorus rate, leaching fraction and substrate influence on influent quantity, effluent nutrient content and response of a containerized woody ornamental crop. HortScience 43:906-912.

Quinn, G.P. and M.J. Keough. 2002. Experimental design and data analysis for biologists. Cambridge University Press, Cambridge, UK.

Sard, E.L. 1989. An experiment with Turface. J. Bromeliad Soc. 39:274-275.

Sturman, M.C. 1999. Multiple approaches to analyzing count data in studies of individual differences: The propensity for type I errors, illustrated with the case of absenteeism prediction. Educ. Psychol. Meas. 59:414-430

Warren, S.L. and T.E. Bilderback. 1992. Arcillite: Effect on chemical and physical properties of pine bark substrate and plant growth. J. Environ. Hort. 10:63-69.

Whitelock, L.M. 2002. The cycads. Timber Press, Portland, OR

Witte, T.W. 1977. Storage and germination of Zamia seed. Proc. Fl. State Hort. Soc. 90:89-91. 